\title{
A ARBORIZAÇÃO URBANA DO MUNICÍPIO DE TIMON/MA: INVENTÁRIO, DIVERSIDADE E DIAGNÓSTICO QUALI-QUANTITATIVO
}

\author{
Lorran André Moraes ${ }^{1}$, Roselis Ribeiro Barbosa Machado²
}

\section{RESUMO}

A arborização urbana é o conjunto da vegetação arbórea natural ou cultivada que uma cidade apresenta. Hoje em dia é uma tendência obrigatória, reconhecida como um serviço urbano essencial que influencia diretamente a qualidade de vida de uma população. Diante disso, o objetivo dessa pesquisa foi inventariar a composição vegetal urbana do Município de Timon-MA, identificando e analisando quali-quantitativamente as espécies vegetais. Nesta pesquisa foram utilizados $20 \%$ do total dos bairros da zona urbana, utilizando o processo amostral, percorrendo algumas das ruas, praças e canteiros centrais de avenidas, no período de fevereiro a julho 2013. Foram identificados 2.319 indivíduos vegetais, distribuídas em 36 famílias, 72 gêneros e 86 espécies. Observou-se que dos 2.319 indivíduos, 1.024 ou 44,15\% apresentam porte médio, seguido por 922 ou 39,75\% que apresentam pequeno porte e ( $n=437$ ou 18.84\%). Foram identificadas 51 espécies nativas e 35 espécies exóticas. Tais informações podem ser úteis ao planejamento da arborização viária do município, contribuindo como subsídio para o direcionamento na tomada de ações a serem realizadas.

Palavras-chave: Vegetação urbana; Inventário; Timon-MA.

\footnotetext{
Recebido em 18.03.2014 e aceito em 10.05.2015
}

1 Biólogo, graduado em Ciências Biológicas - UFPI e UESPI, Pós-graduado em Gestão e Educação Ambiental-UESPI, Professor tutor do Curso de pós-graduação em Gestão e Educação Ambiental do NEAD/UESPI. Colaborador do Grupo de Pesquisa em Paisagismo e Meio Ambiente - NUPEMAP / UESPI. Email: Iorranbio@hotmail.com

2 Bióloga, Doutora em Geografia/UFPE. Professora Adjunta III do Centro de Ciências da Natureza - CCN - UESPI. Coordenadora do Grupo de Pesquisa em Paisagismo e Meio Ambiente - NUPEMAP / UESPI. 


\section{THE URBAN AFFORESTATION IN THE MUNICIPALITY OF TIMON - MA: INVENTORY, DIVERSITY AND QUALITATIVE AND QUANTITATIVE DIAGNOSIS}

\section{ABSTRACT}

The urban afforestation is the set of woody vegetation (natural or cultivated) a city presents. Nowadays it has become a mandatory tendency, recognized as an essential urban service that has direct influence in the quality of life of a population. Thus, the aim of this serch was setting and inventory of the composition of urban vegetation of the township Timon-MA, identifying and analyzing qualitative and quantitative the existing vegetation. In this research, $20 \%$ of the neighborhoods in the urban area were investigated, using the sampling process, covering some of the streets, squares and boulevards, from February to July 2013. We identified 2,319 individuals vegetables, belonging to 36 families, 72 genders and 86 species. It was observed that in 2,319 individuals, 1,024 or $44.15 \%$ are medium-sized, followed by 922 or $39.75 \%$ presenting small size and 370 or $15.95 \%$ of large size. The most common species was the Azadirachta Indicates A. Juss. ( $n=437$ or $18.84 \%$ ). The 51 species were identified, whereas in the exotic origin 35 species were sampled. Such information may be useful for planning the urban afforestation in the city, contributing as a support for guidance in taking actions.

Keywords: Urban vegetation; Inventory; Timon-MA.

\section{INTRODUÇÃO}

De acordo com Sanchotene (1994), cidades são os ambientes mais alterados pela ação do homem, principalmente pela alta concentração de edificações e alta densidade populacional, isso decorre por elas serem os principais centros de poder político, econômico e social, exercendo uma grande atração de pessoas em busca por melhores condições de emprego, educação, lazer, consumo, cultura e de bem estar. Em decorrência disso, há o comprometimento da qualidade de vida de seus habitantes, nas condições climáticas, 
hidrológicas, impermeabilização do solo, poluição (atmosférica, hídrica, sonora e visual) é principalmente na redução da cobertura vegetal urbana (MILANO, 1992).

Devido a esses fatores atualmente, a maioria da população humana vive no meio urbano necessitando, cada vez mais, de condições que possam melhorar a convivência dentro de um ambiente muitas vezes adverso. Utilizar-se dos benefícios da vegetação seria um meio muito cabível, pois a vegetação, pelos vários benefícios que pode proporcionar ao meio urbano, tem um papel muito importante no restabelecimento da relação entre o homem e o meio natural, garantindo melhor qualidade de vida (PIVETTA; SILVA-FILHO, 2002).

Nas últimas décadas a arborização urbana vem constantemente sendo alvo de estudos principalmente em decorrência de seus valores fundamentais no estabelecimento de áreas verdes, devido os pesquisadores entenderem que essas proporcionam uma melhor qualidade de vida às pessoas e, ao mesmo tempo, estreita os laços entre o homem e a natureza (LIMA, et al., 1994).

Arborização urbana ou área verde pode ser definida como o conjunto da vegetação arbórea natural ou cultivada que uma cidade apresenta, estando esta vegetação representada em áreas particulares, parques, praças, vias públicas e em outras áreas verdes complementares (SANCHOTENE, 1994). Nesse contexto a vegetação urbana é aquela que permite que o espaço construído se integre com o jardim e o parque, principalmente nas regiões de climas tropicais e subtropicais úmidos, para construir a paisagem das cidades, sendo sempre seu caráter acrescentado pela ação do homem (MASCARÓ; MASCARÓ, 2002).

A forma adequada de se conhecer o patrimônio arbóreo existente, bem como identificar os possíveis conflitos existentes é por meio da realização de um inventário, o qual possibilitará a obtenção de um diagnóstico da arborização, passo essencial para embasar quaisquer projetos futuros que envolvam alterações no espaço físico local. Por meio do inventário das espécies, pode-se chegar a um diagnóstico mais preciso da arborização, que será obtido analisando-se os dados coletados, contemplando a quantidade de cada espécie presente na arborização, bem como os principais problemas e possíveis soluções (VERVLOT-FILHO et al., 2011).

A arborização urbana deve passar por um planejamento criterioso considerando vários aspectos do ambiente urbano para que não haja conflito da vegetação com as estruturas urbanas, selecionando espécies adequadas para cada local e prezando pela boa diversidade. Assim, a implantação de árvores na paisagem urbana tenderá a proporcionar somente benefícios (VERVLOT-FILHO et al., 2011). 
Nos últimos anos a arborização urbana passou a ser vista como um serviço, exigindo assim normas e especificações técnicas para a sua implantação e manejo em prol da prosperidade da vegetação urbana, para isso, é necessário que cada cidade disponha de um plano diretor de arborização esse constitui uma ferramenta básica com um conjunto de métodos e medidas adotadas para a preservação, manejo e expansão da rede verde viária em cidades, variando a metodologia adotada de acordo com o porte e os recursos disponíveis para tal (SANCHOTENE, 1994). De acordo com Oliveira-Júnior et al., (2011), o panorama das pesquisas em arborização urbana no Brasil vem crescendo, sendo a maioria dos estudos realizados nas regiões Sul e Sudeste, em especial nos estados de São Paulo, Paraná e Rio de Janeiro.

A arborização urbana é uma tendência obrigatória numa época em que se reconhece como um serviço urbano essencial que influencia diretamente a qualidade de vida de uma população, sendo essa melhor á medida em que as administrações públicas optam por priorizar a arborização urbana (SANCHOTENE, 1994).

A arborização urbana como parte da botânica aplicada vem sendo ultimamente um campo com possibilidades ilimitadas de pesquisas, sendo necessário apenas que as espécies sejam estudadas experimentalmente suas características e potencial de introdução na arborização urbana (MELLO-FILHO, 1985). Apesar da grande diversidade de espécies da flora brasileira, nem todas as espécies de árvores da flora prestam-se para o plantio em áreas urbanas. Muitas apresentam porte muito elevado ou raízes muito volumosas, outras possuem frutos muito grandes ou quebram galhos facilmente com o vento oferecendo risco a população (LORENZI, 2002).

Observando que são complexos todos esses fatores para a escolha da espécie adequada, ou seja, as características que a árvore deve apresentar para uma boa arborização urbana de uma cidade, e de difíceis formas muitas vezes de serem plantadas tanto pelos órgãos públicos bem como pela população. Diante do exposto, o objetivo desse trabalho foi inventariar a composição arbórea urbana do Município de Timon-MA, identificando e analisando as espécies vegetais.

\section{MATERIAIS E MÉTODOS}

\section{Caracterização da área de estudo}


O município de Timon-MA, localiza-se á $05^{\circ} 05^{\prime}$ de latitude sul e $42^{\circ} 50^{\prime}$ de longitude Oeste, estando $69 \mathrm{~km}$ acima do nível do mar, distante $426 \mathrm{~km}$ de São Luís por rodovia e, em linha reta, apenas $322 \mathrm{~km}$. Apresenta uma área de 1.743,246 km² com uma população de 155.460 habitantes, e densidade demográfica de 89,18 hab/ $\mathrm{km}^{2}$. O município está situado na microrregião geográfica de Caxias, Mesorregião do Leste Maranhense e Região de Planejamento do Médio Parnaíba, à margem esquerda do rio Parnaíba, limitando-se ao leste com Teresina a capital do Piauí, onde faz parte da Região Integrada de Desenvolvimento da Grande Teresina (Região Metropolitana de Teresina), ao norte e ao oeste com o município de Caxias, e ao sul com o município de Matões. O município encontra-se inserido no bioma cerrado e apresenta um clima Tropical seco (IBGE, 2012).

\section{Metodologia}

A área de estudo escolhida foi a zona urbana do município de Timon-MA, composta por 46 bairros, distribuídos em duas zonas (Sul e Norte). Nesta pesquisa foram utilizados $20 \%$ do total dos bairros, ou seja, os dez principais, a saber: Cajueiro, Centro, Formosa, Parque Alvorada, Parque Piauí, Parque União, Santo Antônio, São Benedito, São Marcos e Vila do Bec (Figura 1).

Figura 1. Mapa de delimitação da zona urbana do Município de Timon - MA, com detalhe da das áreas amostradas no inventário.

Figure 1. Boundary map of the urban area in the city of Timon - MA, with detail of the areas sampled in the inventory.

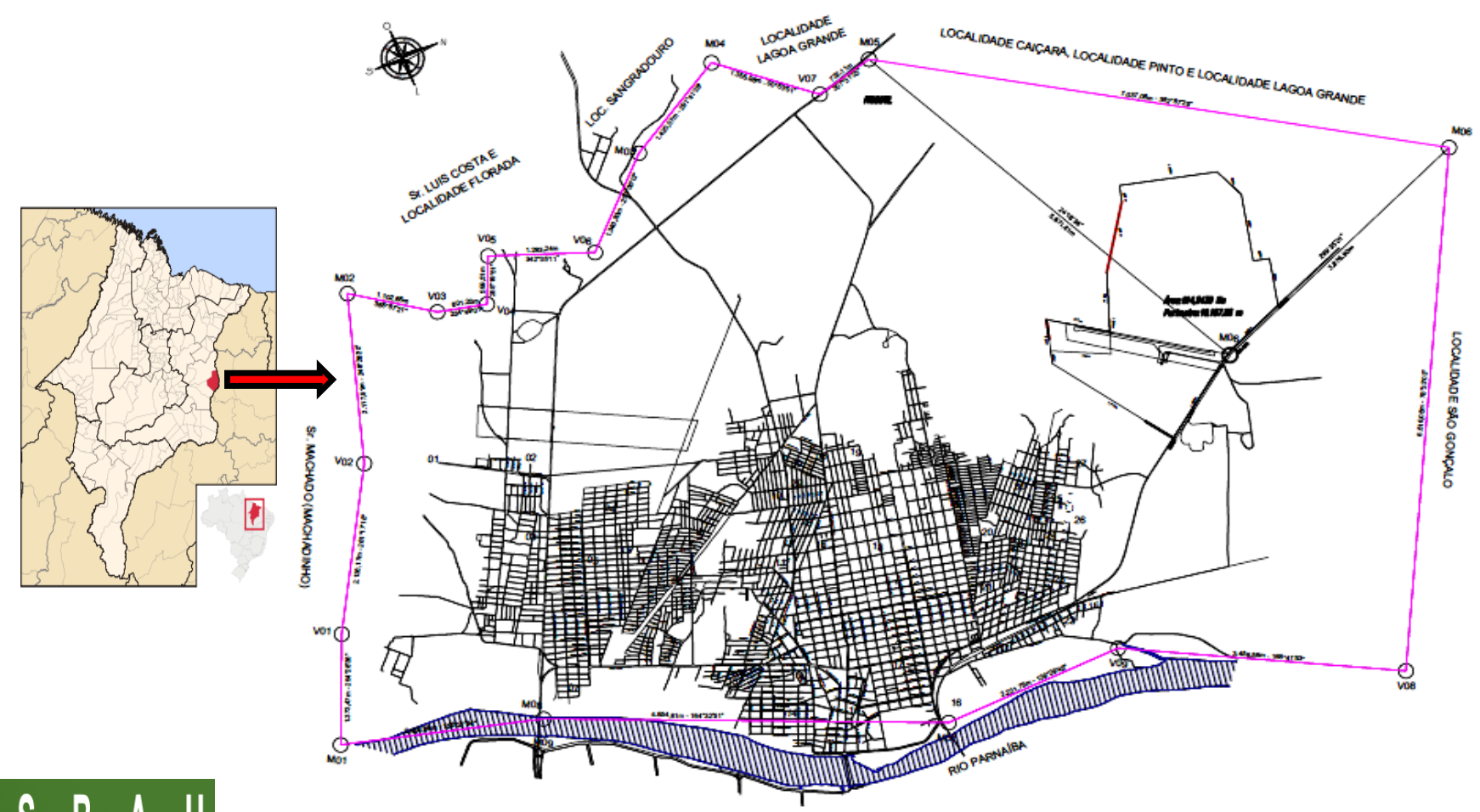


Fonte: Adaptado da Secretaria de infra-estrutura do município de Timon-MA (2013

O tipo de inventário utilizado deve ser em função dos objetivos especificamente definidos, fundamentados em diferentes metodologias e graus de precisão e todos os dados devem constar em uma ficha objetiva e especialmente elaborada pela equipe técnica, em função dos dados desejados. As amostras e cálculos estatísticos devem ser obtidas por estimativas gerais baseadas em avaliações feitas em partes da população, utilizando parcelas amostrais (MILANO; DALCIN, 2000). Nesse sentido, o diagnóstico da arborização foi realizado utilizando o processo amostral, ou seja, feito percorrendo mais de $40 \%$ de algumas das ruas, praças e canteiros centrais de avenidas dos dez bairros escolhidos, avaliando-se todas as árvores com levantamento (identificação) das espécies arbóreas e arbustivas. Apenas foram excluídos os pertencentes às áreas residenciais e privadas.

O levantamento de campo foi realizado no período de março de 2013 a julho 2013. Os dados foram coletados em formulário específico (planilha de levantamento de campo) cada rua/avenida visitada teve seu nome e localização anotados e suas árvores listadas, registrando-se a espécie (comum e científico), o nome da rua, o número do imóvel de referência onde se encontra a árvore, o bairro, a largura da rua e calçada e as características que expressem seu estado atual (com vitalidade - a; e sem vitalidade, danos físicos, interferências com fiação - b).

Nessa pesquisa as espécies foram identificadas, e para todos os espécimes foram apreciados os seguintes aspectos: nome popular; nome científico; família botânica; ocorrência natural (nativa ou exótica); circunferência à altura do peito (1,30 m do solo), utilizando fita métrica comum; o porte dos indivíduos, medindo-se a altura com trena, considerando para os indivíduos de pequeno porte a altura até $1,30 \mathrm{~m}$, porte médio a altura entre 1,30 até 6 metros e grande porte acima de $6 \mathrm{~m}$, foram ainda estimadas as árvores de grande porte; a frequência (\%) foi calculada através da razão entre número de indivíduos da espécie e o número total de indivíduos. Os dados coletados foram tabulados no software Microsoft Office Excel 2007.

As condições da sanidade das árvores foram analisadas conforme Rodolfo-Júnio, et al. (2008) para as seguintes categorias: 0 - árvore morta, quando apresenta danos irreversíveis de pragas, doenças ou graves danos físicos; 1 - árvore muito doente, apresentando estado geral de declínio que podem ser severos danos de pragas, doenças ou defeitos físicos e, não aparentando morte iminente, podendo requerer muito trabalho e 
tempo para a recuperação; 2- árvore que apresenta sinais de pragas doenças ou danos físicos, necessitando de poda corretiva, reparo de danos físicos ou controle sanitário; 3 árvore sã e que não apresenta sinais de pragas doenças ou injurias mecânicas.

Com relação aos danos devido a podas, os indivíduos foram alocados em três categorias conforme Rodolfo-Júnio et al. (2008), foram elas: 0 - inexistente; 1 - fracos e recuperáveis; 2 - fortes e recuperáveis. Já com relação à interferência da copa, os indivíduos foram alocados em cinco categorias, foram elas: 0 - sem interferências; 1 - no transito de pedestres; 2 - no transito de veículos; 3 - na iluminação publica e 4- na fiação.

De acordo com o diâmetro da projeção da copa, levaram-se em considerações os seguintes aspectos: $P$ - copa de pequeno porte, até $3 \mathrm{~m} ; \mathrm{M}$ - copa de médio porte, de $3 \mathrm{~m}$ até $7 \mathrm{~m} ; \mathrm{G}$ - copa de grande porte, acima de $7 \mathrm{~m}$.

A identificação e classificação das espécies botânicas foram realizadas através de estruturas vegetativas e reprodutivas, quando necessária foi acompanhada a fenologia do indivíduo. Os exemplares coletados foram identificados através de literatura específica (BACKES; IRGANG, 2004; CARVALHO, 2003; LEITMAN et al., 2010; LORENZI, 1998; LORENZI, 1999; LORENZI, 2002; LORENZI et al., 2004; SOUSA et al., 2008; SOUZA; LORENZI, 2008) e o sistema de taxonomia botânica utilizado para as famílias foi o APG II (SOUSA; LORENZI, 2008).

\section{RESULTADOS E DISCUSSÃO}

A vegetação arbórea amostrada da cidade de Timon-MA e representada por 2.319 indivíduos, como mostrado na (Tabela 1). As espécies identificadas ficaram distribuídas em 36 famílias, 72 gêneros e 86 espécies (Tabela 1).

Tabela 1. Relação das espécies arbóreo-arbustivos amostrados segundo nome popular e científico, família, ocorrência ( $N$ - nativa; $E$ - exótica) e valores de frequência absoluta (FA) e relativa (FR) da arborização dos bairros amostrados do município de Timon-MA/Brasil, 2013.

Table 1. List of trees and bushes species sampled according to their popular and scientific name, family, occurrence ( $\mathrm{N}$ - native; $\mathrm{E}$ - exotic) and absolute frequency values $(A F)$ and relative frequency (RF) of the afforestation of the sampled districts of the municipality of Timon -MA / Brazil, 2013.

\begin{tabular}{c|c|l|c|c|c|c}
\hline № & NOME VULGAR & \multicolumn{1}{|c|}{ NOME CIENTíFICO } & FAMÍLIA & $\begin{array}{c}\text { Ocorrê } \\
\text { ncia }\end{array}$ & FA & $\begin{array}{c}\text { FR } \\
\text { (\%) }\end{array}$ \\
\hline 1 & Abacateiro & Persea americana Mill. & Lauraceae & Exótica & 01 & 0.04 \\
\hline 2 & Castanha-de-macaco & Couroupita guianensis Aubl. & Lecythidaceae & Nativa & 05 & 0.21 \\
\hline
\end{tabular}




\begin{tabular}{|c|c|c|c|c|c|c|}
\hline 3 & Acerola & Malpighia sp L. & Malpighiaceae & Exótica & 09 & 0.39 \\
\hline 4 & Algodão & $\begin{array}{l}\text { Cochlospermum vitifolium (Willd.) } \\
\text { Spreng. }\end{array}$ & Bixaceae & Nativa & 39 & 1.68 \\
\hline 5 & Amêndoa & Terminalia catappa L. & Combretaceae & Exótica & 295 & 12.7 \\
\hline 6 & Alamanda & Allamanda polyantha Mull. Arg. & Apocynaceae & Nativa & 03 & 0.13 \\
\hline 7 & Alamanda & Allamanda cathartica Linn & Apocynaceae & Exótica & 04 & 0.17 \\
\hline 8 & Angico-preto & $\begin{array}{l}\text { Anadenanthera macrocarpa (Vell.) } \\
\text { Brenam }\end{array}$ & Fabaceae & Nativa & 16 & 0.70 \\
\hline 9 & Angico-preto & $\begin{array}{l}\text { Anadenanthera colubrina (Vell.) } \\
\text { Brenam }\end{array}$ & Fabaceae & Nativa & 04 & 0.17 \\
\hline 10 & Angico-branco & Anadenanthera peregrina (L.) Speg. & Fabaceae & Nativa & 04 & 0.17 \\
\hline 11 & Amoreira & Morus nigra L. & Rosaceae & Exótica & 02 & 0.09 \\
\hline 12 & Amburana-de-cheiro & Amburana cearenses A.C. Smith. & Fabaceae & Nativa & 01 & 0.04 \\
\hline 13 & Ata & Annona squamosa L. & Annonaceae & Exótica & 17 & 0.73 \\
\hline 14 & Azeitona & Syzigium jambolanum (Lam.) D.C & Myrtaceae & Exótica & 20 & 0.87 \\
\hline 15 & Algaroba & Prosopis juliflora D.C. & Fabaceae & Nativa & 94 & 4.05 \\
\hline 16 & Bananeira & Musa paradisiaca L. & Musaceae & Exótica & 01 & 0.04 \\
\hline 17 & Babaçu & Attalea speciosa Mart. & Arecaceae & Nativa & 01 & 0.04 \\
\hline 18 & Brasileirinho & Erythrina indica Picta & Fabaceae & Exótica & 22 & 0.95 \\
\hline 19 & Bambum & Bambusa sp Mutis ex Caldas & Poaceae & Exótica & 12 & 0.51 \\
\hline 20 & Buriti & Mauritia flexuosa L. F. & Arecaceae & Nativa & 09 & 0.39 \\
\hline 21 & Chuva-de-ouro & Cassia fistula $\mathrm{L}$. & Fabaceae & Nativa & 07 & 0.30 \\
\hline 22 & Cafezinho & Ixoria macrothyrsa L. & Rubiaceae & Exótica & 09 & 0.39 \\
\hline 23 & Cajá & Spondias mombim L. & Anacardiaceae & Nativa & 02 & 0.09 \\
\hline 24 & Cajá-grande & $\begin{array}{l}\text { Spondias mombim var. globosa } \\
\text { J.D. Mitch. \& D.C. Daly }\end{array}$ & Anacardiaceae & Nativa & 01 & 0.04 \\
\hline 25 & Cajú & Anacardium ocidentale L. & Anacardiaceae & Exótica & 30 & 1.30 \\
\hline 26 & Carnaúba & $\begin{array}{l}\text { Copernifera prurifera (Miller) H. E. } \\
\text { Moore }\end{array}$ & Arecaceae & Nativa & 114 & 4.91 \\
\hline 27 & Canafistula & $\begin{array}{l}\text { Cassia ferruginea (Schrad.) Schrad. } \\
\text { ex D.C. }\end{array}$ & Fabaceae & Nativa & 02 & 0.09 \\
\hline 28 & Caneleiro & Cenostigma macrophyllum Tul. & Fabaceae & Nativa & 97 & 4.18 \\
\hline 29 & Carambola & Averrhoa carambola L. & Oxalidaceae & Exótica & 01 & 0.04 \\
\hline 30 & Ciriguela & Spondias purpúrea L. & Anacardiaceae & Nativa & 01 & 0.04 \\
\hline 31 & Coqueiro & Cocos nucifera L. & Arecaceae & Nativa & 01 & 0.04 \\
\hline 32 & Cróton & Codiaeum variegatum Blume & Euphorbiaceae & Exótica & 03 & 0.13 \\
\hline 33 & Chapéu-de-napoleão & Theventia nereifolia Juss. & Apocynaceae & Nativa & 54 & 2.32 \\
\hline 34 & Chuveiro-de-ouro & Lophanthera lactescens Ducke & Malpighiaceae & Nativa & 02 & 0.09 \\
\hline 35 & Espirradeira & Nerium oleander $\mathrm{L}$. & Apocynaceae & Exótica & 05 & 0.21 \\
\hline 36 & Espinheiro & $\begin{array}{l}\text { Mimosa bimucronata (DC.) O. } \\
\text { Kuntze }\end{array}$ & Fabaceae & Nativa & 04 & 0.13 \\
\hline 37 & Farinha-seca & Albizia hasslerri (Chodat) Burr. & Fabaceae & Nativa & 35 & 1.50 \\
\hline 38 & Faveira-de-bolota & Parkia platycephala Benth. & Fabaceae & Nativa & 01 & 0.04 \\
\hline 39 & Flamboyant & Delonix regia (Boy.) Raf. & Fabaceae & Exótica & 12 & 0.51 \\
\hline 40 & Fedegoso & $\begin{array}{l}\text { Senna macranthera (Collad.) Irwin } \\
\text { et Barn. }\end{array}$ & Fabaceae & Nativa & 09 & 0.39 \\
\hline 41 & Figueira & Ficus benjamina L. & Moraceae & Exótica & 95 & 4.09 \\
\hline 42 & Figueira-rajada & Ficus benjamina var. benjamina L. & Moraceae & Exótica & 03 & 0.13 \\
\hline 43 & Falsa-seringueira & $\begin{array}{l}\text { Ficus benjamina var. bracteata } \\
\text { Corner }\end{array}$ & Moraceae & Exótica & 01 & 0.04 \\
\hline 44 & Goiabeira & Psidium guajava L. & Mirtaceae & Nativa & 18 & 0.78 \\
\hline 45 & Gonçalo-alves & $\begin{array}{l}\text { Astronium fraxinifolium Schott ex } \\
\text { Spreng. }\end{array}$ & Anacardiaceae & Nativa & 01 & 0.04 \\
\hline 46 & Ipê-amarelo & Handroanthus sp. Mattos & Bignoniaceae & Nativa & 66 & 2.85 \\
\hline 47 & Imbaúba & Cecropia pachystachya Trec. & Cecropiaceae & Nativa & 01 & 0.04 \\
\hline 48 & Ingá & Inga uruguensis Hooker at Arnott & Mimosaceae & Nativa & 01 & 0.04 \\
\hline
\end{tabular}




\begin{tabular}{|c|c|c|c|c|c|c|}
\hline 49 & Ipê-roxo & $\begin{array}{l}\text { Handroanthus impetiginosa (Mart. } \\
\text { ex DC.) Mattos }\end{array}$ & Bignoniaceae & Nativa & 44 & 1.90 \\
\hline 50 & Ipezinho & Tecoma stans (L.) H.B.\& k. & Bignoniaceae & Nativa & 12 & 0.51 \\
\hline 51 & Jatobá & $\begin{array}{l}\text { Hymeneae courbaril L.var. } \\
\text { stilbocarpa (Hayne) Lee et Lang. }\end{array}$ & Fabaceae & Nativa & 01 & 0.04 \\
\hline 52 & Jambo & Jambo malaccensis D.C & Myrtaceae & Exótica & 31 & 1.34 \\
\hline 53 & Jasmim & Plumeria rubra Linn & Apocynaceae & Exótica & 11 & 0.47 \\
\hline 54 & Jenipapo & Genipa americana L. & Rubiaceae & Nativa & 03 & 0.13 \\
\hline 55 & Júa & Ziziphus joazeiros Mart. & Rhamnaceae & Nativa & 02 & 0.09 \\
\hline 56 & Yuca & Yucca elephantipes Regel & Liliaceae & Exótica & 01 & 0.04 \\
\hline 57 & Laranjeira & Citrus aurantium L. & Rutaceae & Exótica & 22 & 0.95 \\
\hline 58 & Limão & Citrus lemon (L.) Burm. F. & Rutaceae & Exótica & 05 & 0.21 \\
\hline 59 & Macaúba & Acrocomia aculeata (Jacq.) Lodd. & Arecaceae & Nativa & 1 & 0.04 \\
\hline 60 & Margarida & Hibiscus rosa-sinensis Linn. & Malvaceae & Exótica & 02 & 0.09 \\
\hline 61 & Mamurana & Pachira aquatica Aubl. & Bombacaceae & Nativa & 128 & 5.52 \\
\hline 62 & Mangueira & Mangifera indica L. & Anacardiaceae & Exótica & 121 & 5.17 \\
\hline 63 & Mandacaru & Cereu sp Mill. & Cactaceae & Nativa & 01 & 0.04 \\
\hline 64 & Mamona & Ricinus communis L. & Euphorbiaceae & Nativa & 04 & 0.17 \\
\hline 65 & $\mathrm{Nim}$ & Azadirachta indica A. Juss. & Meliaceae & Exótica & 437 & 18.8 \\
\hline 66 & Noni & Morinda citrifolia L. & Rubiaceae & Nativa & 02 & 0.19 \\
\hline 67 & Oiti & Licania tomentosa (Benth.) Fristsh & $\begin{array}{c}\text { Chrysobalana } \\
\text { ceae }\end{array}$ & Nativa & 153 & 6.60 \\
\hline 68 & Olho-de-pombo & Adenanthera pavonina L. & Fabaceae & Exótica & 16 & 0.70 \\
\hline 69 & Pau-brasil & Guilandina echinata (Lam.) Spreng. & Fabaceae & Nativa & 05 & 0.21 \\
\hline 70 & Pau-d'água & Terminalia sp L. & Combretaceae & Nativa & 25 & 1.08 \\
\hline 71 & Pau-ferro & $\begin{array}{l}\text { Caesalpinia ferrea Mart.ex Tul. var. } \\
\text { férrea }\end{array}$ & Fabaceae & Nativa & 10 & 0.43 \\
\hline 72 & Palmeira-areca & Dypsis lutescens (H. Wendl.) & Arecaceae & Exótica & 07 & 0.30 \\
\hline 73 & Palmeira-samambaia & Cycas circinalis Roxb. & Cycadaceae & Exótica & 03 & 0.13 \\
\hline 74 & Pata-de-vaca & Bauhinia longifolia (Bong.) Steud. & Fabaceae & Nativa & 06 & 0.26 \\
\hline 75 & Pião-roxo & Jatropha curcas L. & Euphorbiaceae & Nativa & 04 & 0.17 \\
\hline 76 & Pião-branco & Jatropha mollissima (Pohl) Baill. & Euphorbiaceae & Nativa & 01 & 0.04 \\
\hline 77 & Pingo-de-ouro & Duranta repens L. & Verbenaceae & Exótica & 13 & 0.56 \\
\hline 78 & Primavera & $\begin{array}{l}\text { Bougainvillea spectabilis var. glabra } \\
\text { ( Choisy) Hook. }\end{array}$ & Nyctaginaceae & Nativa & 01 & 0.04 \\
\hline 79 & Primavera & Bougainvillea glabra Choisy & Nyctaginaceae & Nativa & 01 & 0.04 \\
\hline 80 & Pitomba & Talisia esculenta (St. Hill) Radik. & Sapindaceae & Nativa & 02 & 0.09 \\
\hline 81 & Romãzeira & Punica granatum $\mathrm{L}$. & Lythraceae & Exótica & 01 & 0.04 \\
\hline 82 & Sapucaia & Lecythis pisonis Camb. & Lecythidaceae & Nativa & 01 & 0.04 \\
\hline 83 & Sombreiro & Clitoria fairchildiana Howard & Fabaceae & Nativa & 26 & 1.12 \\
\hline 84 & Surucucu & Piptadenia viridiflora (Kunth) Benth. & Fabaceae & Nativa & 58 & 2.50 \\
\hline 85 & Tamarindo & Tamarindus indica L. & Fabaceae & Exótica & 22 & 0.95 \\
\hline 86 & Tamboril & $\begin{array}{l}\text { Enterolobium contortisiliquum (Vell.) } \\
\text { Morong }\end{array}$ & Fabaceae & Nativa & 03 & 0.13 \\
\hline \multicolumn{5}{|c|}{ TOTAL } & 2319 & $\begin{array}{c}100 \\
\%\end{array}$ \\
\hline
\end{tabular}

De acordo com os resultados exposto na tabela 1, pode-se afirmar que as famílias botânicas mais abundantes/frequentes identificadas foram: Fabaceae ( $n=453$ indivíduos ou 19,54\%); Meliaceae ( $n=437$ indivíduos ou 18,84\%); Combretaceae ( $n=320$ indivíduos ou 13,79\%); Anacardiaceae ( $n=156$ indivíduos ou 6,68\%); Chrysobalanaceae ( $n=153$ indivíduos ou 6,60\%); Arecaceae ( $n=133$ indivíduos ou 5,72\%); Bombacaceae ( $n=128$ 
indivíduos ou 5,52\%) e Bignoneaceae ( $n=122$ indivíduos ou 5,26\%). As demais famílias foram menos abundantes e apresentaram entre um e cem indivíduos, como o caso da Moraceae ( $n=99$ indivíduos ou 4,26\%).

A família com o maior número de espécie foi a Fabaceae (23 espécies e 19 gêneros), seguida da Arecaceae com (6 espécies e 6 gêneros), Anacardiaceae (6 espécies e 4 gêneros), Apocynaceae (5 espécies e 4 gêneros), Euphorbiaceae (4 espécies), com 3 espécies as famílias; Bignoniaceae, Myrtaceae, Moraceae e Rubiaceae (3 espécies), e com duas espécies as famílias; Rutaceae, Nyctaginaceae, Malpighiaceae, Lecythidaceae, Combretaceae. As demais famílias estão representadas apenas por uma espécie botânica.

As dez espécies mais representativas foram Azadirachta indica A. Juss. (niim, $n=$ 437 ou 18.84\%), Terminalia catappa L. (amendoeira, $n=295$ ou 12,72\%), Licania tomentosa (Benth.) Fristsh (oiti, $\mathrm{n}=153$ ou 6,60\%), Pachira aquatica Aubl. (mamurana, $\mathrm{n}=128$ ou $5,52 \%$ ), Mangifera indica L. (mangueira $=121$ ou 5,17\%), Copernifera prurifera (Miller) $\mathrm{H}$. E. Moore (carnaúba, $\mathrm{n}=114$ ou 4.91\%), Cenostigma macrophyllum Tul. (caneleiro, $\mathrm{n}=97$ ou $4,18 \%$ ), Ficus benjamina L. (fícus, $n=95$ ou 4,09\%), Prosopis juliflora DC. (algaroba, $n=94$ ou 4,05\%) e Handroanthus sp Mattos (ipê amarelo, $n=66$ ou 2,85\%).

Das 86 espécies identificadas na arborização de ruas e praças em relação à vegetação nativa, foram identificadas 51 espécies ( $n=1019$ indivíduos ou 43,9\%), enquanto que na de origem exótica amostrou-se 35 espécies ( $n=1300$ indivíduos ou 56,1\%). Também foram identificadas 27 espécies frutíferas, sendo 15 de árvores exóticas e 12 nativas. Dentre as espécies exóticas as que apresentam valor alimentício animal e humano, tais como, o Abacateiro (Persea americana Mill.), Acerola (Malpighia sp. L.), Amoreira (Morus nigra L.), Ata (Annona squamosa L.), Azeitona preta (Syzigium jambolana (Lam.) D.C), Bananeira (Musa paradisiaca L.), Cajú (Anacardium ocidentale L.), Carambola (Averrhoa carambola L.), Jambo (Jambo malaccensis D.C), Laranjeira (Citrus aurantium L.), Limão (Citrus limon (L.) Burm. F.), Mangueira (Mangifera indica L.), Pitomba (Talisia esculenta (St. Hill) Radik.), Romãzeira (Punica granatum L.), Tamarindo (Tamarindus indica L.), dentre outras, como mostra a tabela 1. Algumas dessas espécies frutíferas não são recomendadas para a arborização viária, podendo causar alguns problemas a cidade (ALBERTIN et al., 2011).

Percebeu-se ainda nessa pesquisa que houve uma grande diferença quanto à ocorrência de árvores entre bairros, sendo o bairro Centro o que obteve a maior quantidade de indivíduos amostrados, $\mathrm{n}=566$ ou 24, 40\% (sendo destes 90 indivíduos da espécie Terminalia catappa L.- amendoeira), seguido pelo Bairro São Benedito, com 486 indivíduos ou 20,95\% (84 indivíduos da espécie Azadirachta indica A. Juss.- niim), o Parque Alvorada, com 402 ou 17,33\% (103 indivíduos da espécie Azadirachta indica A. Juss.- niim), Parque 
Piauí, com 318 ou 13,71\% (102 indivíduos da espécie Copernifera prurifera (Miller) H. E. Moore - carnaúba), e os demais em menor quantidade como a Formosa com 164 ou 7,07\%, Santo Antônio com 88 ou 3,79\%, São Marcos com 82 ou 3,53\%, Parque União com 77 ou $332 \%$, Cajueiro com 65 ou 2,80\% e o Vila do Bec com apenas $n=48$ ou $2,06 \%$.

Observou-se que dos 2.319 indivíduos presentes na vegetação urbana por bairro amostrado no Município de Timon-MA, 1.024 ou 44,2\% apresentaram porte médio, seguido por 922 ou $39,8 \%$ que apresentam pequeno porte e 370 ou $16 \%$ que são de grande porte (Tabela 2). A porcentagem por bairro fica demonstrada ainda na mesma tabela.

Tabela 2. Porte arbóreo da vegetação urbana por bairro amostrado no Município de Timon-MA

Table 2. Scale of the urban tree vegetation sampled by neighborhood in the city of Timon

\begin{tabular}{lcccccc}
\hline \multicolumn{1}{c}{ BAIRROS } & \multicolumn{5}{c}{ PORTE } \\
& P-pequeno & M-médio & G- grande & TOTAL & $\%$ \\
\hline Cajueiro & 18 & 36 & 7 & 65 & 2,80 \\
Centro & 275 & 196 & 93 & 564 & 24,40 \\
Formosa & 45 & 83 & 41 & 169 & 7,82 \\
Parque Alvorada & 162 & 195 & 46 & 402 & 17,33 \\
Parque Piauí & 142 & 124 & 50 & 318 & 13,71 \\
Parque União & 43 & 36 & 18 & 97 & 4,18 \\
São Benedito & 166 & 248 & 72 & 486 & 25,26 \\
Santo Antonio & 27 & 43 & 18 & 88 & 3,79 \\
São Marcos & 24 & 45 & 13 & 82 & 3,53 \\
Vila do Bec & 20 & 18 & 10 & 48 & 2,06 \\
\hline \multicolumn{1}{c}{ TOTAL } & $\mathbf{9 2 2 /}$ & $\mathbf{1 0 2 4 /}$ & $\mathbf{3 7 0 /}$ & $\mathbf{2 3 1 9}$ & $\mathbf{1 0 0 \%}$ \\
\multicolumn{1}{c}{$\%$} & $39,8 \%$ & $\mathbf{4 4 , 2 \%}$ & $16 \%$ & & \\
\hline
\end{tabular}

Destaca-se também, grande diferença quanto à ocorrência de árvores entre as diferentes ruas do município, sendo a Avenida 3 a que obteve a maior quantidade de indivíduos amostrados, $\mathrm{n}=298$ (sendo destes 93 indivíduos da espécie Licania tomentosa (Benth.) Fritsch - Oiti), seguido pela avenida Luiz Firmino de Sousa, com 158 indivíduos (48 indivíduos da espécie Cenostigma macrophyllum Tul. - Caneleiro) sendo ambas as ruas no bairro São Benedito, e da avenida Paulo Ramos do bairro Centro com 143 indivíduos (27 indivíduos da espécie Azadirachta indica A. Juss - Niim).

Nesse estudo de amostragem da vegetação arbórea em dez principais bairros do município de Timon-MA, foram identificados 2319 indivíduos, distribuídas em 36 famílias, 72 gêneros e 86 espécies. Observou-se que dos 2.319 indivíduos, 1.024 ou 44,15\% apresentam médio porte, seguido por 922 ou 39,75\% que apresentam pequeno porte e 370 ou 15,95 de grande porte. As três espécies mais frequentes foram Azadirachta indica (niim, 
$\mathrm{n}=437$ ou 18,84\%), Terminalia catappa L. (amendoeira, $\mathrm{n}=295$ ou 12,72\%), Licania tomentosa (Benth.) Fristsh (oiti, $\mathrm{n}=153$ ou 6,60\%). A família botânica mais abundante identificada foi a Fabaceae com 453 indivíduos ou 19,54\%, sendo também a com maior número de espécie com 23 espécies e 19 gêneros.

A praça melhor arborizada foi a São José com 82 indivíduos, as espécies identificadas ficaram distribuídas em 13 famílias, 16 gêneros e 19 espécies. As espécies mais representativas foram a (mangueira) - Mangifera indica Linn. representada por 28 indivíduos e o (oiti) - Licania tomentosa (Benth.) Fritsch com 17 indivíduos. Em seguida a Praça do Parque Alvorada com 63 indivíduos, distribuídos em 21 famílias, 24 gêneros e 26 espécies. Observou-se que dos 63 indivíduos, 20 ou 55,55\% apresentam médio porte, seguido por 35 ou $31,74 \%$ que apresentam pequeno porte e $08 /$ ou $2,69 \%$ de grande porte. Em relação à vegetação nativa, foram identificadas 16 espécies ( $n=42$ indivíduos ou $66,67 \%$ ), enquanto que na de origem exótica amostrou-se 10 espécies ( $n=21$ indivíduos ou $33,33 \%)$.

Diante desses resultados e comparando com outras cidades do mesmo porte apresentadas em estudos científicos, pode-se concluir que a cidade é bem provida de uma expressiva variabilidade de espécies. Essa diversidade das espécies no meio urbano é fundamental para contribuir com a melhoria da estética do ambiente e redução de ataques de pragas (MILANO, 1990). Neste aspecto, Santamour-Júnior, (1990) determina que não se deva ter mais de $10 \%$ de uma única espécie de árvore; não mais de $20 \%$ de um único gênero de árvore; não mais de $30 \%$ de espécies da mesma família.

Com relação à densidade das espécies amostradas, verifica-se na tabela 1 que a espécie Azadirachta indica A. Juss. (Níim) foi à espécie com maior frequência de indivíduos ( $n=437$ ou 18,84\%). De acordo com as recomendações de uso de espécies vegetais na arborização urbana cada espécie não deve ultrapassar $10-15 \%$ do total de indivíduos da população para um bom planejamento (MILANO; DALCIN, 2000; GREY; DENEKE, 1978), neste caso, a espécie está fora do padrão proposto pelos pesquisadores. Fato que se torna grave caso uma única praga e/ou doença atingir aquela espécie dominante e assim prejudicar toda essa arborização (ALBERTIN et al., 2011), assim os autores afirmam que, deste modo, os riscos ficam mais distribuídos, evitando que a arborização de ruas de uma cidade seja dizimada por um surto de pragas e doenças. Pode-se observar que o Níim corresponde a $18,84 \%$ do total. Desta forma, a composição da arborização de vias públicas de Timon-MA está focada, principalmente, nesta espécie. O vegetal está presente na arborização da cidade recentemente, devido á facilidade de aquisição das mudas, bem 
como, a boa adaptação no ambiente urbano, e o desconhecimento da população a respeito da biologia da espécie.

Pode-se assim afirmar segundo Dantas e Souza, (2004) que é extremamente essencial que a escolha da espécie a ser colocada no meio urbano seja realizada de forma correta e planejada, visto que o uso indevido de plantas pode acarretar em problemas futuros relacionados à população e empresas que prestam serviços de rede elétrica, telefonia, esgotos, entre outros. Entre esses fatores citam-se a compactação e impermeabilização do solo devido à pavimentação, poluição do ar, que impede a folha de exercer livremente suas funções principais, podas drásticas e abertura de valas junto à árvore, mutilando o seu sistema radicular (MILANO; DALCIN, 2000; GREY; DENEKE, 1978), ou seja, a escolha das espécies adequadas a serem utilizadas no meio urbano deve ser baseada em suas características estruturais e estéticas, ecológicas, químicas e genéticas (PAIVA, 2009).

A espécie Azadirachta indica A. Juss. (Níim), é um vegetal de procedência exótica originária da Ásia, natural de Burma e das regiões áridas da Índia. Ocorrem em diversos países, causando múltiplos efeitos ruins, principalmente alterações no desenvolvimento e comportamento dos insetos. No Brasil está sendo amplamente usada na arborização principalmente pelo rápido crescimento e desenvolvimento nas regiões áridas. No entanto, embora apresente crescimento rápido e bom sombreamento, poderá contribuir para alterações ecológicas no meio, modificando até a flora local (VALE et al., 2011).

A espécie Terminalia catappa L. (Amendoeira) foi à segunda espécie com maior frequência de indivíduos ( $n=295$ ou 12,72\%). De acordo com as recomendações de uso para arborização urbana a espécie esta dentro do padrão proposto por (MILANO; DALCIN, 2000; GREY; DENEKE, 1978), pois não ultrapassou os $10-15 \%$ do total de indivíduos. O mesmo ocorre com as outras 86 espécies identificadas nesse estudo.

Não é incomum na arborização de algumas cidades brasileira a presença da amendoeira (Terminalia catappa L.), oitizeira (Licania tomentosa (Benth.) Fristsh) e do ficus (Ficus benjamina L.), por exemplo, na cidade São João Evangelista-MG em um total de 814 árvores recenseados, constatou-se que o maior número de árvores encontradas foi da espécie Licania tomentosa Benth. ( $n=499)$, seguido do gênero Ficus $L$. $(n=49)$, Terminalia catappa L. com 43 indivíduos (BRANDÃO et al., 2011). Já em Nova Esperança - PA das 74 espécies e 8.908 indivíduos, a oitizeira (Licania tomentosa com $n=1333$ ou 14,96\%) e Monguba (Pachira aquática Aubl. com $n=236$ ou 2,65\%) e fícus (Ficus benjamina L. com $n=$ 83 ou 0,93\%) (ALBERTIN et al., 2011). 
A espécie Licania tomentosa (Benth.) Fritsch - (oitizeira), é um vegetal que pode atingir altura entre 8 e 15 metros, sendo uma árvore muito utilizada na arborização urbana e viária, devido, principalmente, à copa frondosa. Todavia, ela requer cuidados especiais, principalmente nos aspectos de poda. Devem-se podar os galhos que estão ligados ao tronco de $1,60 \mathrm{~m}$ até $1,80 \mathrm{~m}$. Assim, as árvores irão se desenvolver sem comprometer a passagem de pedestres e veículos. Além dela, o fícus (Ficus benjamina L.), outra espécie muito comum nos logradouros da cidade, apresenta um grande valor ornamental pelas folhas e pela forma geral da planta, podendo ser utilizados tanto em jardins como em interiores. Não é recomendado para a arborização viária, pois o sistema radicular danifica drasticamente vias de passeio, ruas e avenidas (ALBERTIN et al., 2011). A figueira é um vegetal de origem exótico e apresenta crescimento rápido e raízes que podem causar inúmeros danos gera muitos problemas na arborização como o tombamento de outras árvores, rachaduras de calçamento e construções (BOENI; SILVEIRA, 2011).

Em relação à vegetação nativa, foram identificadas 51 espécies $(n=1.019$ indivíduos ou $43,9 \%$ ), enquanto que na de origem exótica amostrou-se 35 espécies ( $n=1.300$ indivíduos ou 56,1\%). Esse resultado demonstra que a arborização das cidades brasileiras é realizada em sua maioria por espécies que não pertencem aos biomas locais, embora a diferença entre elas não tenha sido expressiva como cita Camilo et al. (2013), em estudo da arborização em Guaxupé - MG, que amostrou 55,05\% exóticas e 44,95\% nativas. Na cidade de Aracaju, Sergipe, no levantamento da arborização encontrou-se em vias públicas 66 espécies, sendo que do total, 61\% representam espécies exóticas (SANTOS et al., 2011). Em Senador Guiomard no Acre, o levantamento censitário da arborização urbana viária identificou 16 espécies, sendo dos indivíduos, 88,3\% de espécies exóticas (MARANHO et al., 2012). Na Estância de Águas de São Pedro em São Paulo, Bortoleto et al. (2007) inventariaram 161 espécies, que dentre estas $61,33 \%$ eram exóticas.

Os parâmetros estados fitossanitários, diâmetro da projeção da copa, danos devido a podas e interferência da copa, também foram avaliados (Figura 2). Com relação ao tamanho da copa das árvores, 1.074 ou (46,3\%) foram de árvores com copa pequena, 832 ou (35,9\%) de copa média e de 413 ou (17,8\%) árvores com copa grande (Figura 2a). Já para estado fitossanitário, 36 ou $(1,6 \%)$ de árvores mortas, 291 ou $(12,5 \%)$ de árvores muito doente ou atacada, 393 ou (16,9\%) de árvores apresentando sintomas de doenças ou ataque leve, e 1.599 ou (69\%) de árvores sã (Figura 2b). Para danos devidos a podas, 1.264 ou $(54,5 \%)$ com dano inexistente, 814 ou (35.1\%) fracos e recuperáveis, 241 ou $(10,4 \%)$ fortes e irrecuperáveis (Figura 2c). 
Ao analisar o estado fitossanitário dos indivíduos inventariados, observa-se que $69 \%$ das às árvores foram classificadas como de bom estado ou sã. E sobre a interferência da copa, 1.230 ou (66\%) das árvores sem interferência, 478 ou (20,6\%) árvores com interferência no transito de pedestre, 15 ou $(0,64 \%)$ no transito de veículos, 53 ou (2,3\%) na iluminação pública e 243 ou (10,5\%) na fiação (Figura 2d). Para Melo et al. (2007), plantio de árvores nas cidades deve ser compatibilizado com a fiação aérea existente na malha urbana.

Figura 2. Aspecto da arborização nos bairros da zona urbana do Município de Timon $M A$, quanto a (o): estado fitossanitário (A); diâmetro da projeção da copa (B); danos devido a podas $(\mathrm{C})$; interferência da copa (D).

Figure 2. Appearance of trees in the neighborhoods of the urban area of the city of Timon $M A$, as (the) plant health (A); diameter of the canopy projection (B); damage due to cuttings $(C)$; interference of the crown (D).
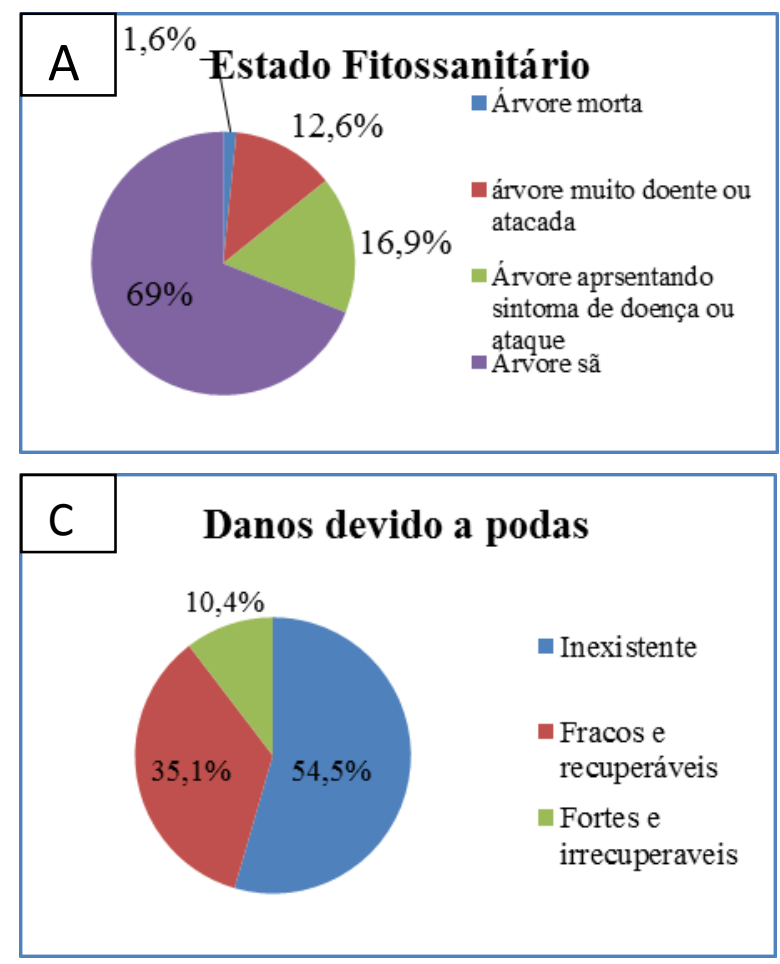
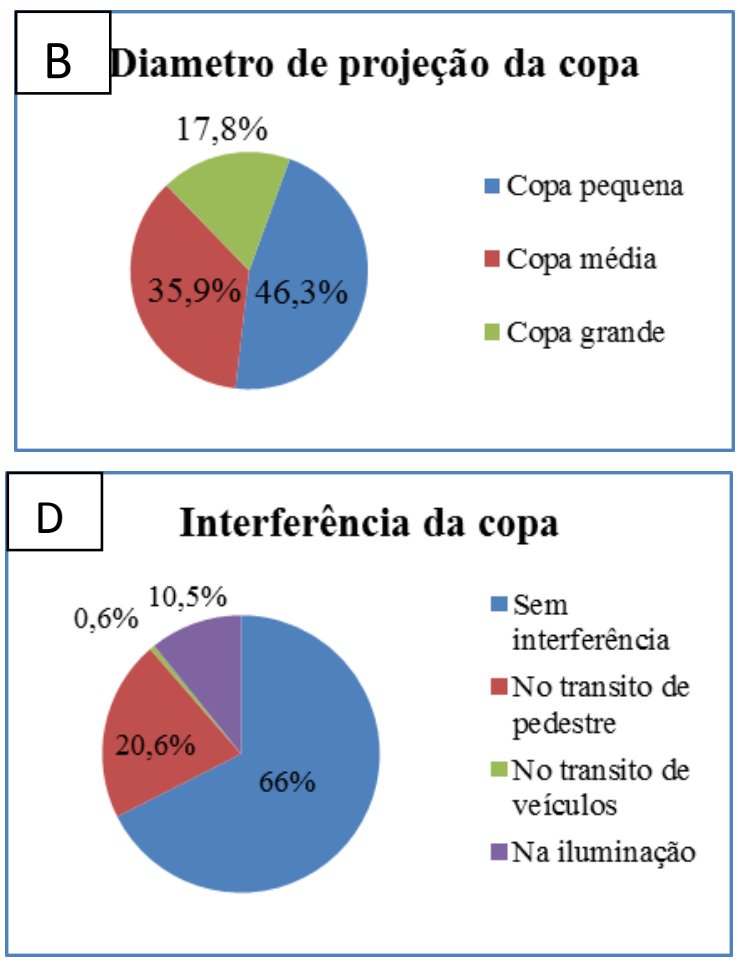

Das árvores avaliadas observou-se que 35,1\% necessitavam de algum tipo de poda, principalmente a poda leve, também conhecida como poda de formação ou de limpeza. No entanto, apenas $10,4 \%$ dos indivíduos necessitavam de uma poda drástica ou pesada. De acordo com Melo et al. (2007) é notório hoje em dia que as podas das árvores urbanas devam ser feitas pelo gestor público, e que estas podem ser evitadas quando moradores cuidam da arborização de seus próprios bairros, a exemplo dos estudos realizados pelos 
autores na cidade Patos-PB, onde constataram que quase $68 \%$ das árvores não necessitavam de podas devido a cuidados tomados pelos moradores do bairro.

\section{CONCLUSÕES}

Nesse estudo de inventário da vegetação arbórea urbana em dez principais bairros do município de Timon-MA, foram identificados 2.319 indivíduos, distribuídas em 36 famílias, 72 gêneros e 86 espécies. Observou-se que dos 2.319 indivíduos, 1.024 ou 44,15\% apresentam médio porte, seguido por 922 ou $39,75 \%$ que apresentam pequeno porte e 370 ou 15,95 de grande porte. As três espécies mais frequentes foram Azadirachta indica A. Juss. (niim, $n=437$ ou 18,84\%), Terminalia catappa L. (amendoeira, $n=295$ ou 12.72\%), Licania tomentosa (Benth.) Fristsh (oiti, $n=153$ ou 6,60\%). A família botânica mais abundante identificada foi a Fabaceae com 453 espécimes ou 19,54\%, sendo ainda e a com maior número de espécie com 23 espécies e 19 gêneros. Das 86 espécies identificadas na arborização em relação à vegetação nativa, foram identificadas 51 espécies $(n=1.019$ indivíduos ou $43,9 \%$ ), enquanto que na de origem exótica amostrou-se 35 espécies ( $n=$ 1.300 indivíduos ou 56,1\%). Também foram identificadas 27 espécies frutíferas, sendo 15 de árvores exóticas e 12 nativas. Percebeu-se ainda nesse inventário que houve uma grande diferença quanto à ocorrência de árvores entre bairros, sendo o bairro Centro o que obteve a maior quantidade de indivíduos amostrados, $\mathrm{n}=566$ ou $24,40 \%$ (sendo destes 90 indivíduos da espécie Terminalia catappa L.).

A pesquisa possibilitou constatar que o município de Timon não possui um planejamento técnico da arborização adequado, sendo que a grande quantidade de espécies nativas diagnosticadas na arborização da cidade e a priori devido à iniciativa própria da população para seu plantio de forma aleatória, e também pode ser explicado pelos primeiros incentivos da prefeitura pela manutenção do verde viário. Com isso, percebe-se que é necessário um planejamento urgente na arborização do município com um número mais adequado de indivíduos por espécie.

\section{REFERÊNCIAS}

ALBERTIN, R. M.; ANGELIS, R.; ANGELIS-NETO, G.; ANGELIS, B. L. D. Diagnóstico qualiquantitativo da arborização viária de Nova Esperança, Paraná, BRASIL. Revista da Soc. Bras. de Arborização Urbana. Piracicaba - SP, v.6, n.3, p.128-148, 2011. 
BACKES, P.; IRGANG, B. Árvores cultivadas no sul do Brasil: guia de identificação e interesse paisagístico das principais espécies exóticas. Porto Alegre: Paisagem do sul, 2004.

BOENI, B. O e SILVEIRA, D. Diagnóstico da arborização urbana em bairros do município de porto alegre, RS, BRASIL. Revista da Soc. Bras. de Arborização Urbana. Piracicaba SP, v.6, n.3, p.189-206, 2011.

BORTOLETO, S.; SILVA-FILHO, D. F. da; SOUZA, V. C.; FERREIRA, M. A. de P.; POLIZEL, J. L.; RIBEIRO, R. de C. S. Composição e distribuição da arborização viária da Estância de Águas de São Pedro-SP. Revista da Soc. Bras. de Arborização Urbana. Piracicaba - SP, v. 2, n. 3, 2007.

BRANDÃO, I. M. GOMES, L. B.; SILVA, N. C. A. R.; FERRARO, A. C.; SILVA, A. G.; GONÇALVES, F. G. Análise quali-quantitativa da arborização urbana do um município de São João Evangelista-MG. Revista da Soc. Bras. de Arborização Urbana. Piracicaba SP, v.6, n.4, p.158-174, 2011.

CAMILO, G. A. P. V.; BREGAGNOLI, M.; SOUSA, C. A. S. Levantamento da biodiversidade florística da arborização urbana em Guaxupé - Minas Gerais. Revista Agrogeoambiental. Pouso Alegre, v.5, n.1, p. 61-74, abr. 2013.

CARVALHO, P. E. R. Espécies Arbóreas Brasileiras. Brasília: Embrapa Informação Tecnológica; Colombo: Embrapa Florestas, v.1, 1039 p, 2003.

DANTAS, I. C.; SOUZA, C. M. C. de. Arborização urbana na cidade de Campina Grande PB: Inventário e suas espécies. Revista de Biologia e Ciências da Terra. Sergipe- SE. EDUEP - UEP. v. 4, n. 2, p. 1-19 2004.

IBGE. Instituto Brasileiro de Geografia e Estatística. Disponível em: <http://cidades. ibge.gov.br/xtras/perfil.php?codmun=211220>. Acesso em: 18 de abril de 2013.

LEITMAN, P.; HENDERSON, A.; NOBLICK, L. Lista de Espécies da Flora do Brasil. Jardim Botânico do Rio de Janeiro. Disponível em: <http://floradobrasil.jbrj.gov.br/>. Acesso em: 04 de Mar. 2015

LIMA, A. M. L. P.; CAVAlHEIRO, F.; NUCCI, J. C.; SOUSA, M. A. L.; FIALHO, N. O.; PICCHIA, P. C. D. Problemas de utilização na conceituação de termos como espaços livres, áreas verdes e correlatos. In: Congresso Brasileiro de Arborização Urbana, II, 1994, São Luís/MA. Anais... São Luís/MA, p.539-553.1994,

LORENZI, H.; Árvores brasileiras: Manual de identificação e cultivo de plantas arbóreas nativas do Brasil. v 2, 2 ed. Nova Odessa. São Paulo, Editora: Plantarum, p. 352,1998 . 
LORENZI, H. Árvores brasileiras: manual de identificação e cultivo de plantas arbóreas do Brasil. 2. ed. Nova Odessa: Instituto Plantarum, v. 2, 368p, 2002.

LORENZI, H. Plantas ornamentais no Brasil: arbustivas, herbáceas e trepadeiras. v 1, 2 ed. Nova Odessa. São Paulo, Editora: Plantarum, 1088p, 1999.

LORENZI, H.; SOUZA, H. M.; MEDEIROS-COSTA, J. T.; CERQUEIRA, L. S. C.; FERREIRA, E. Palmeiras Brasileiras e Exóticas Cultivadas. São Paulo, Editora Plantarum, 432p, 2004.

LORENZI, H. Árvores Brasileiras: Manual de identificação e cultivo de plantas arbóreas do Brasil. Vol. 2. 3. ed. Nova Odessa: Instituto Plantarum, 2008.

MASCARO, L.; MASCARO, J. Vegetação Urbana. Porto Alegre: UFRGS, [s.n.] 2002.

MARANHO, A. S.; PAULA, S. R. P.; LIMA, E.; PAIVA, A. V.; ALVES, A. P.; NASCIMENTO, D. O. Levantamento censitário da arborização urbana viária de Senador Guiomard, Acre. Revista da Soc. Bras. de Arborização Urbana. Piracicaba-sp, v. 7, n. 3, p. 44-56, 2012.

MELLO-FILHO, L. E. Arborização urbana. In: Encontro Nacional Sobre Arborização Urbana, 1985, Porto Alegre. Contribuições técnicas científicas. Anais... Porto Alegre: PMPA/SMMA, p. 117-127, 1985.

MELO, R. R.; FILHO, J.A.; RODOLFO JÚNIOR, F. Diagnóstico qualitativo e quantitativo da arborização urbana no bairro Bivar Olinto, Patos, Paraíba. Revista da Sociedade Brasileira de Arborização Urbana. Piracicaba-SP. v.2, n.1, 2007, p.64-78.

MILANO, M. S. Planejamento da arborização urbana: relações entre áreas verdes e ruas arborizadas. In: Encontro Brasileiro Sobre Arborização Urbana. Anais... Curitiba-PR: Sociedade Brasileira de Arborização Urbana, p. 244-251.1990.

MILANO, M. S. A cidade, os espaços abertos e a vegetação. In: Congresso Brasileiro sobre Arborização Urbana, 1ํ Encontro Nacional sobre Arborização Urbana, 4. 1992, Anais... Vitória-ES, (s. $\left.n^{\circ}\right)$, p. 3-14, 1992.

MILANO, M.; DALCIN, E. Arborização de vias públicas. Rio de Janeiro: LIGHTH, p. 226, 2000.

OLIVEIRA-JÚNIOR, M. M. O.; SILVA, M. I. O.; MELO, L. L. S.; VASCON ELOS, L. G. L.; SOUSA, W. Análise quali-quantitativa de espécies arbóreas encontradas no Parque Santana, Recife-PE. In: 15ํㅡㄹ Congresso Brasileiro e 1ํㅡ Congresso lbero-americano de Arborização Urbana- CBAU. Anais... Recife- PE, 2011. 
PAIVA, A. V. Aspectos da arborização urbana do Centro de Cosmópolis - SP. Revista da Sociedade Brasileira de Arborização Urbana, Piracicaba v. 4, n. 4, p. 17-31, 2009.

PIVETTA, K. F. L e SILVA-FILHO, D. F. Arborização urbana. Boletim acadêmico série arborização urbana. UNESP/FCAV/FUNEP. Jaboticabal, SP, 69p, 2002.

SANCHOTENE, M. C. C. Desenvolvimento e perspectivas da Arborização Urbana no Brasil. In: II Congresso Brasileiro de Arborização Urbana; V Encontro Nacional sobre Arborização Urbana. Anais... São Luiz-MA: SBAU, p. 15 - 25,1994.

SANTAMOUR-JÚNIOR, F. S. Trees for urban planting: diversity uniformity, and common sense. In: Metria Conference, 7., 1990, Lisle. Proceedings... Lisle: 1990 p.57-66. Disponível em: $\quad$ <http://www.ces.ncsu.edu/fletcher/programs/nursery/metria/metria07/m79.pdfLisle.> Acesso em 16 maio. 2013.

SANTOS, C. Z. A.; FERREIRA, R. A.; SANTOS, L. R.; SANTOS, L. I.; GRAÇA, D. A. S.; GOMES, S. H.; PORTO NETO, W. B.; CORREIA, T. S.; BOSCHESE, A. C. B. Composição florística de 25 vias públicas de Aracaju - SE. Revista da Sociedade Brasileira de Arborização Urbana. Piracicaba, v. 6, n. 2, p. 125-144, 2011.

SANTOS-JÚNIOR, M. A. S. VIANA, S.M.; BARROS, L. G. O. Segundo panorama das pesquisas em arborização urbana no Brasil. In: 15ำ Congresso Brasileiro e 1ํ Congresso Ibero-americano de Arborização Urbana- CBAU, 2011. Anais... Recife- PE, 2011.

SOUZA, H. M.; LORENZI, H. Botânica Sistemática: guia ilustrado para identificação das famílias de fanerógamas nativas e exóticas no Brasil, baseado em APG II. Nova Odessa: Instituto Plantarum. 704p, 2008.

TIMON, P. M. Secretaria Municipal de Obras e Infraestrutura. Disponível em: $<$ http://www.timon.ma.gov.br/secretaria/secretaria-municipal-de-obras-e-infraestrutura/>. Acesso em 13 de julho de 2013.

VALE, N. F. L.; SOUSA, G. S.; MATA, M. F.; BRAGA, P. E. T. Inventário da arborização do parque da cidade do município de Sobral, Ceará. Revista da Soc. Bras. de Arborização Urbana. Piracicaba - SP, v.6, n.4, p.145-157, 2011.

VERVLOT-FILHO, R. H. V.; PLASTER, O. B.; SILVA, A. G. Aspectos florísticos da arborização do campus de goiabeiras da Universidade Federal do Espírito Santo. In: 15을 Congresso Brasileiro e 1ํㅡㄹ Congresso Ibero-americano de Arborização Urbana- CBAU, 2011, Anais... Recife- PE, 2011. 